\title{
Can Bladder Irrigation Reduce the Morbidity of Bladder Stone in Patients with Spinal Cord Injury?
}

\author{
Hui Chen ${ }^{1 *}$, Keji Xie ${ }^{2}$, Chonghe Jiang ${ }^{3}$, Xinghua Yang', Jingwen Zeng' ${ }^{3}$, Maping Huang ${ }^{4}$, \\ Qiuling Liu', Jiebing Huang", Tianhai Huang ${ }^{4}$, Yanfeng Li ${ }^{4}$, Jing Liu', Shumei Xie4 \\ ${ }^{1}$ Department of Urology, Guangdong Provincial Work Injury Rehabilitation Hospital and Jinan University, \\ Guangzhou, China \\ ${ }^{2}$ Department of Urology, Guangzhou First Municipal People's Hospital, Guangzhou, China \\ ${ }^{3}$ Department of Urology, Qingyuan People's Hospital, Qingyuan, China \\ ${ }^{4}$ Department of Spinal Cord Injury Recovery Center, Guangdong Provincial Work Injury Rehabilitation Hospital, \\ Guangzhou, China \\ Email: "doc.chenhui@163.com
}

Received 18 March 2015; accepted 16 April 2015; published 17 April 2015

Copyright (C) 2015 by authors and Scientific Research Publishing Inc.

This work is licensed under the Creative Commons Attribution International License (CC BY).

http://creativecommons.org/licenses/by/4.0/

(c) (i) Open Access

\begin{abstract}
Objective: To assess the safety and efficacy of bladder irrigation for reducing the morbidity of bladder stones in patients with neurological lower urinary tract dysfunction (NLUTD). Methods: From June 2012 to July 2013, patients with NLUTD were prospectively randomized and assigned to either a bladder irrigation group or a no bladder irrigation group. Bladder irrigations were performed twice a week by urologists. Patients were followed up at 6 months respectively. Primary outcomes were Incontinence-Specific Quality-of-Life Instrument (I-QoL), the rate incidences of bladder stone. All adverse events were also noted. Results: A total of 80 eligible patients participated and $78(97.5 \%)$ patients (bladder irrigation, $n=39$; no bladder irrigation, $n=39$ ) completed 24 weeks of follow-up. Out of the 78 patients, $19(24.3 \%)$ developed bladder stones. All occurred in no bladder irrigation group. In 8 of the 19 patients $(42.1 \%)$, stones were only detected by cystoscopy. The bladder stones were mostly thin with an eggshell appearance $\mathbf{7 8 . 9 5 \%}$ for diameter of stone $<5 \mathrm{~mm}, 84.21 \%$ for volume of bladder stone $<0.2 \mathrm{~cm}^{3}$ ). Bladder stones were removed by vigorous bladder irrigation guided by ultrasound $(73.68 \%)$ or endoscopic lithotripsy (26.32\%). The I-QOL was significantly better in the bladder irrigation group than in no bladder irrigation group at weeks $6,12,18$, and 24 of follow-up. Conclusion: Bladder irrigation may be more effective and safer than no bladder irrigation for reducing the morbidity of bladder stone in spinal cord injury patients.
\end{abstract}

\footnotetext{
${ }^{*}$ Corresponding author.
}

How to cite this paper: Chen, H., Xie, K.J., Jiang, C.H., Yang, X.H., Zeng, J.W., Huang, M.P., Liu, Q.L., Huang, J.B., Huang, T.H., Li, Y.F., Liu, J. and Xie, S.M. (2015) Can Bladder Irrigation Reduce the Morbidity of Bladder Stone in Patients with Spinal Cord Injury? Open Journal of Urology, 5, 42-47. http://dx.doi.org/10.4236/oju.2015.54007 


\section{Keywords}

\section{Bladder Irrigation, Bladder Stone, Spinal Cord Injury}

\section{Introduction}

Bladder stones are a common secondary urological complication in patients with spinal cord injury (SCI) [1] [2]. It can negatively affect patients' quality of life and cause a variety of complications, such as catheter blockage, urinary retention, autonomic dysreflexia (T6 and above), hematuria, recurrent urinary tract infections, and impaired renal function [3]. Although bladder stones can be surgically removed, preventive measures remain a challenge for urologists. The use of bladder irrigation is usually recommended to remove the encrustation or blood clots after urological surgery [4]. Sinclair and colleagues [5] concluded from a meta-analysis that bladder irrigation was not beneficial for patients. However, the including studies [6]-[10] focused less on SCI patients who undergo intermittent catheterization (IC) [11] which has become the standard procedure for managing neurogenic lower urinary tract dysfunction (NLUTD).

In this trail, we reported the 6 months of follow-up results of a randomized prospective trial to evaluate whether bladder irrigation help decrease the rate of bladder stone in patients with neurological lower urinary tract dysfunction (NLUTD).

\section{Materials and Methods}

From June 2012 to July 2013, 80 patients suffered from NLUTD at the urology department in Guangdong provincial work injury rehabilitation hospital were included in this study. Patients were randomized and assigned to either the regular bladder irrigation or no bladder irrigation.

A urology registrar, who was not participating in the procedure, enrolled the patients and assigned them to treatment based on a randomization schedule from random-number tables balanced in blocks of ten. The protocol was approved by hospital ethics committee.

Before this trail, all patients required two weeks training by a senior urological professional nurse, then perform skillfully on clean intermittent self-catheterization (CISC). The CISC was performed as follows: 1) Find a comfortable position; 2) Wash hands and genitals thoroughly with soap and water; 3) Hold the penis towards the umbilicus, and wash external urethral meatus with soap and a clean washcloth; 4) Rinse the 12F silicone catheters with warm water; 5) Slowly and gently insert the catheter into the urethra; 6) Keep the catheter in place until the flow of urine stops; 7) Slowly and gently withdraw the catheter ; 8) Clean and store the catheter. The frequency of IC is 4 - 6 times per day; the bladder volume is below $400 \mathrm{ml}$ [12].

Bladder irrigation was carried out twice each week by senior urological nurses according to the following standardized protocol: 1) explain the reason and the procedure to the patient; 2) insert a two-way or three-way catheter (16F - 22F) with using of aseptic technique; 3) Place blue sheet under the catheter and drainage bag connection, unsterile jug on bottom of trolley; 4) Clean catheter and drainage bag connection with chlorhexidine wipes, disconnect and wrap the drainage bag end in a chlorhexidine swab and if possible give to the patient to hold; 5) Use a Catheter tip $50 \mathrm{ml}$ syringe and Sterile normal saline to irrigate the catheter by flushing in and drawing back to evacuate any clot or debris; 6 ) the intake volume should not exceed the patient's bladder safety volume according to urodynamics in order to protect the upper urinary tract; 7) empty each returned syringe directly into the unsterile jug on the bottom of the trolley; 8) bladder irrigation procedure was performed twice a week.

Patients were followed up at 6 months respectively. The outcome of this trail includes Incontinence-SpecificQuality-of-Life Instrument (I-QoL) [12], the rate of bladder stone, symptomatic urinary tract infection (Symptomatic UTI), and other adverse event. I-QoL [12] at baseline and during weeks 2, 6, 12, 18, and 24 of follow-up. The I-QoL contains 22 items evaluating problems related to incontinence. Items are scored on a 5-point scale with values ranging from 1 (extreme) to 5 (not at all). Scores were then converted to a scale ranging from 0 (worst I-QoL) to 100 (best I-QoL). All patients underwent ultrasonography and abdominal radiographs by a consultant radiologist at weeks 4, 8, 12, 16, 20, and 24 of follow-up. Symptomatic UTI [13] was defined as a positive urine microbiology test and presence of at least one of the following clinical features or symptoms with 
no other recognized cause: 1) Fever, a temperature higher than $38^{\circ} \mathrm{C}$; 2) New or increased burning sensation on urination, urgency; 3) New flank or suprapubic pain or tenderness; 4) Hematuria.

Data were recorded and analysized on a SPSS13.0 statistical program (SPSS, Inc., Chicago, IL). Student’s t-test was used for comparison of related variables and results which was expressed in mean \pm standard deviation. The chi-square test was used for categorical data. $\mathrm{P}<0.05$ was considered statistically significant.

\section{Results}

Eighty eligible cases were randomly assigned to bladder irrigation $(n=41)$ or no bladder irrigation group $(n=$ 39). Two patients in the bladder irrigation group (C7 AIS A, T2 AIS A) were lost to follow-up at 1 month because they developed autonomic dysreflexia during the irrigation procedure .Therefore, a total of 78 (97.5\%) patients (bladder irrigation , $\mathrm{n}=39$; no bladder irrigation, $\mathrm{n}=39$ ) completed 6 months of follow-up.

There was no statistical differences between the groups for any of baseline characteristics (Table 1). Out of a total of 78 patients, 19 (24.3\%) developed bladder stones requiring medical intervention. All occurred in the no bladder irrigation group (Table 2). 8 (42.1\%) bladder stones were not detected by either ultrasound or abdominal radiographs. The mean time period to stone development was 4.12 months of follow-up and ranged from 3.1 to 5.4 months. The bladder stones were mostly thin with an eggshell appearance. The stone diameter was less than $5 \mathrm{~mm}$ in $78.9 \%$ of the patients and the stone volume was less than $0.2 \mathrm{~cm}^{3}$ in $84.2 \%$ of patients. Bladder stones were removed by vigorous bladder irrigation guided by ultrasound (73.6\%) or endoscopic lithotripsy (26.3\%) (Table 3).

The I-QOL scores were significantly better in the bladder irrigation group than those in no bladder irrigation group at weeks 6, 12, 18, and 24 of follow-up $(\mathrm{P}<0.05)$ (Figure 1).

Table 1. Demographic data of bladder irrigation group and no bladder irrigation group.

\begin{tabular}{|c|c|c|c|}
\hline Variable & Bladder irrigation group & No bladder irrigation group & $\mathrm{P}$ value \\
\hline No. of patients & 39 & 39 & \\
\hline \multicolumn{4}{|l|}{ Gender } \\
\hline Male/female & $22 / 17$ & $20 / 19$ & 0.650 \\
\hline Age (year) & $35.23 \pm 11.63$ & $31.28 \pm 6.25$ & 0.066 \\
\hline Mean \pm s.d. (range) & $(19-54)$ & $(22-49)$ & \\
\hline Duration of spinal cord injury (months) & $8.19 \pm 3.27$ & $9.56 \pm 3.38$ & 0.074 \\
\hline Mean \pm s.d. (range) & $(4.9-15.4)$ & $(5.2-17.8)$ & \\
\hline \multicolumn{4}{|l|}{ level of neurological injury } \\
\hline Tetraplegia/Paraplegia/Conus-Cauda Equina Syndrome & $4 / 19 / 16$ & $8 / 23 / 8$ & 0.112 \\
\hline \multicolumn{4}{|l|}{ AIS scores, n (\%) } \\
\hline AIS-A/B/C/D & $13 / 15 / 9 / 2$ & $16 / 11 / 10 / 2$ & 0.541 \\
\hline
\end{tabular}

AIS, the American social injury association; s.d., standard deviation.

Table 2. Adverse events of the two group in 6 month follow-up.

\begin{tabular}{|c|c|c|c|}
\hline Adverse events, n (\%) & Bladder irrigation group & No bladder irrigation group & $P$ value \\
\hline Bladder stone & 0 & $19(48.72)$ & $<0.0001$ \\
\hline Symptomatic UTI & $3(7.69)$ & $16(41.03)$ & 0.001 \\
\hline Acute epididymo-orchitis & 0 & $3(7.32)$ & 0.07 \\
\hline Catheter obstruction & 0 & 17(43.59) & $<0.0001$ \\
\hline
\end{tabular}

Abbreviations: Symptomatic UTI, symptomatic urinary tract infection. 
Table 3. Characteristics of the bladder stone in no bladder irrigation groups.

\begin{tabular}{|c|c|}
\hline Variable & Value \\
\hline \multicolumn{2}{|l|}{ Diagnosized by } \\
\hline Ultrasonography or abdominal radiographs & 11 \\
\hline Cystoscopy & 8 \\
\hline \multicolumn{2}{|l|}{ The diameter of bladder stone (mm) } \\
\hline$<5$ & 15 \\
\hline $5-10$ & 3 \\
\hline $11-15$ & 1 \\
\hline \multicolumn{2}{|l|}{ The volume of bladder stone $\left(\mathrm{cm}^{3}\right)$} \\
\hline$<0.2$ & 17 \\
\hline $0.2-0.5$ & 1 \\
\hline $0.5-1.0$ & 1 \\
\hline$>1.0$ & 0 \\
\hline \multicolumn{2}{|l|}{ The remove of bladder stone } \\
\hline Bladder irrigation guided by ultrasound & 5 \\
\hline Endoscopic lithotrypsy & 14 \\
\hline
\end{tabular}

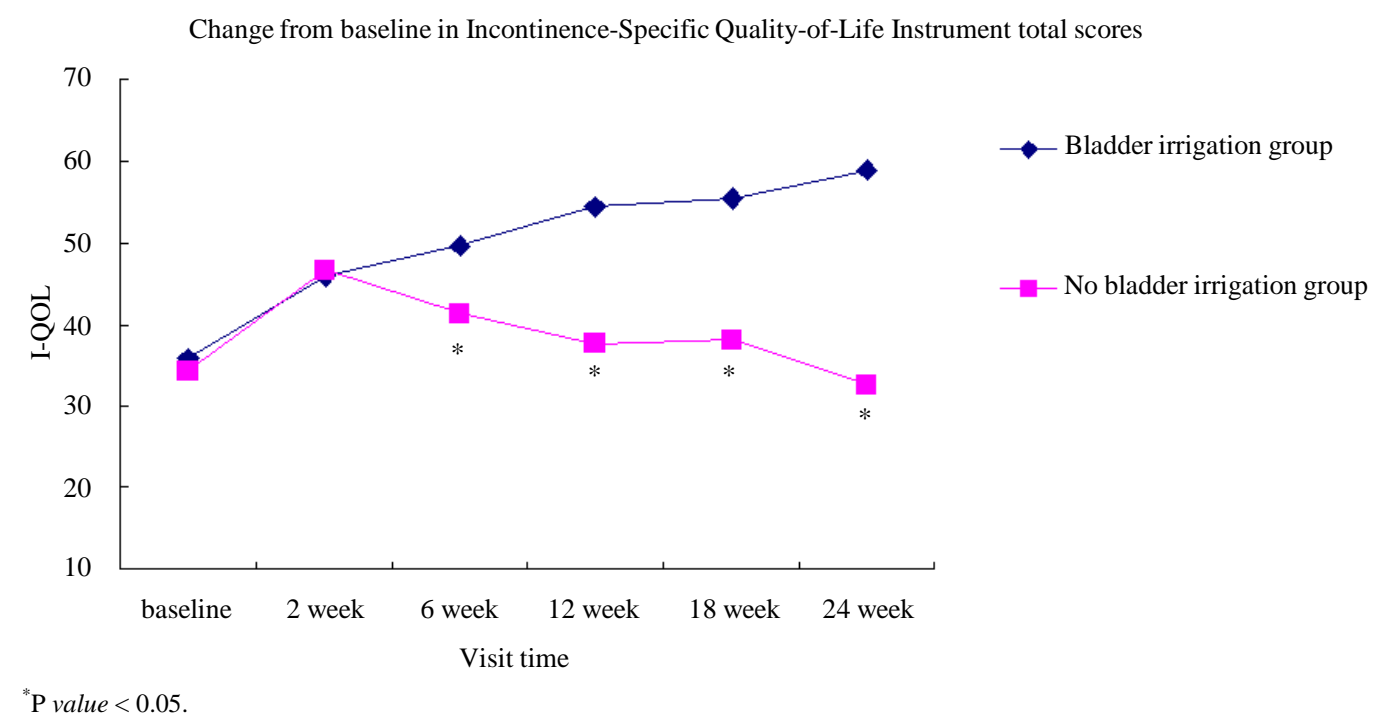

Figure 1. Change from baseline in Incontinence-Specific Quality-of-Life Instrument total scores.

\section{Comment}

In the past 30 years, many alternative approaches have been advocated for the prevention of bladder stones in SCI patients. These include long-term antibiotic therapy, use of ascorbic acid to acidify the urine, increased fluid intake, and the use of silicone or antibiotic-coated catheters. Unfortunately, these approaches have met with only limited success. Clean Intermittent catheterization (CIC), self- or third-party, has been demonstrated to be safe and effective for SCI patients who are unable to empty their bladder [14]. It has been reported that 2\% - 5\% [15] [16] of SCI patients with IC develop bladder stones. Interestingly, the incidence rate of bladder stones in our study was higher (19/78, 24.35\%) than previous studies. The reasons were: 1) 6 of 19 (31.6\%) patients with bladder stones were detected by routine mensual ultrasound examinations without any urinary symptoms because of sensory impairment and vesicourethral dysfunction. A recent study [17] also demonstrated that some 
urinary abnormality was detected by ultrasound in 24 of 87 (27.6\%) SCI patients with no complaints. 2) 8 of 19 (42.1\%) bladder stones were detected by cystoscopy alone. Although cystoscopy is an invasive procedure, it is the "gold standard" [18] to detect bladder stones because noninvasive methods are less reliable in SCI patients. Ultrasound is the primary diagnostic imaging tool for detecting bladder stones. However, image quality may be poor because it is difficult for SCI patients to distend their bladder. Moreover, the distention of the bladder could cause autonomic dysreflexia or bacteremia in SCI patients [19]. Abdominal radiographs are also difficult to detect bladder stones because of small size of stones, abdominal gas, and the composition of bladder stones. In a landmark study, Linsenmeyerand co-workers [20] reported that only 13 of 62 (20.97\%) bladder stones found during cystoscopy were detected by abdominal radiographs. Moreover, regarding the diameter and total volume of stones, the detection by $x$-ray in their series, was $14 \%$ for stones $<0.5 \mathrm{~cm}$, and $0 \%$ for volumes $<0.2 \mathrm{~cm}^{3}$. According to our results, abdominal radiographs detected only 4 (21.05\%) of the bladder stones. 3) 5 of 16 (31.25\%) patients presenting with symptomatic urinary tract infections developed bladder stones. It is widely accepted that urinary tract infections, especially with urease-producing bacteria [21], may lead to an increase in bladder stone formation. Favazza et al. [2] reported that 83\% of SCI patients with bladder stones had a history of urinary infections. The lack of the stones composition is a limitation of our study, and requires further study.

Based on our results, bladder irrigation was superior to no bladder irrigation with respect to reducing the incidence of bladder stone formation; the 19 bladder stones occurred only in no bladder irrigation group. All 1 bladder stones could be removed by vigorous bladder irrigation guided by ultrasound or endoscopic lithotrypsy. The reasons we analyzed for the significant difference between the two groups were: 1) Although patients or their caregivers were instructed for IC, there was still difficult for them to empty bladder completely because of poor catheterization technique. Besides, changes in bladder function and bladder morphology, such as bladder trabeculations, bladder diverticulums, and deformity of bladder shape also lead to residual urine [22]; 2) As the result of residual urine in the bladder, minerals in the urine would form various crystals which result in catheter obstruction and bladder stone formation. Moreover, inadequate emptying is usually associated with urinary tract infections, which are also the risk for the development of bladder stones. Our study shows that no catheter obstruction and 7.69\% symptomatic UTI supported those bladder irrigations help not only to expel the crystals directly, but also reduce the incidence of urinary infection.

The I-QoL differed significantly between the groups at weeks $6,12,18$, and 24 of follow-up $(\mathrm{P}<0.05)$. The reasons are: 1) according to our trial, the patients in the bladder irrigation group showed greater improvement in I-QoL than those in no bladder irrigation group; 2) 17, 19 cases in no bladder irrigation developed catheter obstructions, bladder stones respectively, I-QoL from them were very low; 3) 3 patients with acute epididymoorchitis requiring medical intervention burden the questionnaire.

Lastly, this study focused on whether bladder irrigation led to reduce the morbidity of bladder stone in male SCI inpatients. The sample size was relatively small and the follow-up period was relatively short. Similarly, identification of patients who were at risk for developing bladder stones on the basis of age, degree of spinal cord damage, level of spinal cord injury, duration of spinal cord injury, fell outside the scope of this study. Moreover, the results of this study must be tempered with knowledge that such twice weekly bladder irrigation would increase the cost of treatment.

\section{Acknowledgements}

This study was supported by: 1) Medical Scientific Research Foundation of Guangdong Province, China (grant number A2013477, A2014579); 2) Science and Technology Planning Project of Guangdong Province, China (grant number 2012B031800007).

\section{Conflict of Interest Statement}

The authors declare no conflict of interest.

\section{References}

[1] De Vivo, M.J., Fine, P.R., Cutter, G.R., et al. (1985) The Risk of Bladder Calculi in Patients with Spinal Cord Injuries. Archives of Internal Medicine, 145, 428-430. http://dx.doi.org/10.1001/archinte.145.3.428

[2] Favazza, T., Midha, M., Martin, J., et al. (2004) Factors Influencing Bladder Stone Formation in Patients with Spinal 
Cord Injury. Journal of Spinal Cord Medicine, 27, 252-254.

[3] Ord, J., Lunn, D. and Reynard, J. (2003) Bladder Management and Risk of Bladder Stone Formation in Spinal Cord Injured Patients. Journal of Urology, 170, 1734-1737. http://dx.doi.org/10.1097/01.ju.0000091780.59573.fa

[4] Waites, K.B., Canupp, K.C., Roper, J.F., et al. (2006) Evaluation of 3 Methods of Bladder Irrigation to Treat Bacteriuria in Persons with Neurogenic Bladder. Journal of Spinal Cord Medicine, 29, 217-226.

[5] Sinclair, L., Hagen, S., Cross, S., et al. (2011) Washout Policies in Long-Term Indwelling Urinary Catheterization in Adults: A Short Version Cochrane Review. Neurourology and Urodynamics, 30, 1208-1212. http://dx.doi.org/10.1002/nau.21063

[6] McNicoll, D. (2003) Encrusted Urinary Catheters: How Should Nurses Manage Them? Journal of Community Nursing, 17, 10-14.

[7] Moore, K.N., Hunter, K.F., McGinnis, R., et al. (2009) Do Catheter Washouts Extend Patency Time in Long Term Indwelling Urethral Catheters? A Randomized Controlled Trial of Acidic Washout Solution, Normal Saline Washout, or Standard Care. Journal of Wound Ostomy \& Continence Nursing, 36, 82-90. http://dx.doi.org/10.1097/01.WON.0000345181.37656.de

[8] Waites, K.B., Canupp, K.C., Roper, J.F., et al. (2006) Evaluation of 3 Methods of Bladder Irrigation to Treat Bacteriuria in Persons with Neurogenic Bladder. Journal of Spinal Cord Medicine, 29, 217-226.

[9] Kennedy, A.P., Brocklehurst, J.C., Robinson, J.M., et al. (1992) Assessment of the Use of Bladder Washouts/Instillations in Patients with Long-Term Indwelling Catheters. British Journal of Urology, 70, 610-615. http://dx.doi.org/10.1111/j.1464-410X.1992.tb15829.x

[10] Muncie Jr., H.L., Hoopes, J.M., Damron, D.J., et al. (1989) Once-Daily Irrigation of Long-Term Urethral Catheters with Normal Saline. Lack of Benefit. Archives of Internal Medicine, 149, 441-443. http://dx.doi.org/10.1001/archinte.1989.00390020133028

[11] Hansen, R.B., Biering-Sørensen, F. and Kristensen, J.K. (2004) Bladder Emptying over a Period of 10-45 Years after a Traumatic Spinal Cord Injury. Spinal Cord, 42, 631-637. http://dx.doi.org/10.1038/sj.sc.3101637

[12] Stöhrer, M., Blok, B., Castro-Diaz, D., Chartier-Kastler, E., Del Popolo, G., Kramer, G., et al. (2009) EAU Guidelines on Neurogenic Lower Urinary Tract Dysfunction. European Urology, 56, 81-88. http://dx.doi.org/10.1016/j.eururo.2009.04.028

[13] Wagner, T.H., Patrick, D.L., Bavendam, T.G., Martin, M.L. and Buesching, D.E. (1996) Quality of Life of Persons with Urinary Incontinence: Development of a New Measure. Urology, 47, 67-71. http://dx.doi.org/10.1016/S0090-4295(99)80384-7

[14] McGeer, A., Campbell, B., Emori, T.G., et al. (1991) Definitions of Infection for Surveillance in Long-Term Care Facilities. American Journal of Infection Control, 19, 1-7. http://dx.doi.org/10.1016/0196-6553(91)90154-5

[15] Afsar, S.I., Yemisci, O.U., Cosar, S.N.S. and Cetin, N. (2013) Compliance with Clean Intermittent Catheterization in Spinal Cord Injury Patients: A Long-Term Follow-Up Study. Spinal Cord, 51, 645-649. http://dx.doi.org/10.1038/sc.2013.46

[16] Herr, H.W. (1975) Intermittent Catheterization in Neurogenic Bladder Dysfunction. Journal of Urology, 113, 477-479.

[17] Bartel, P., Krebs, J., Wöllner, J., Göcking, K. and Pannek, J. (2014) Bladder Stones in Patients with Spinal Cord Injury: A Long-Term Study. Spinal Cord, 52, 295-297. http://dx.doi.org/10.1038/sc.2014.1

[18] Vaidyanathan, S., Hughes, P.L. and Soni, B.M. (2006) A Comparative Study of Ultrasound Examination of Urinary Tract Performed on Spinal Cord Injury Patients with No Urinary Symptoms and Spinal Cord Injury Patients with Symptoms Related to Urinary Tract: Do Findings of Ultrasound Examination Lead to Changes in Clinical Management? Scientific World Journal, 6, 2450-2459. http://dx.doi.org/10.1100/tsw.2006.382

[19] Linsenmeyer, T.A. and Culkin, D. (1999) APS Recommendations for the Urological Evaluation of Patients with Spinal Cord Injury. Journal of Spinal Cord Medicine, 22, 139-142.

[20] Binard, J.E., Persky, L., Lockhart, J.L. and Kelley, B. (1996) Intermittent Catheterization the Right Way! (Volume vs. Time-Directed). Journal of Spinal Cord Medicine, 19, 194-196.

[21] Linsenmeyer, M.A. and Linsenmeyer, T.A. (2004) Accuracy of Bladder Stone Detection Using Abdominal X-Ray after Spinal Cord Injury. Journal of Spinal Cord Medicine, 27, 438-442.

[22] Mobley, H.L. and Warren, J.W. (1987) Urease-Positive Bacteriuria and Obstruction of Long-Term Urinary Catheters. Journal of Clinical Microbiology, 25, 2216-2217. 